\section{Sweetening antibiotic treatments}

\section{By Chris Cain, Staff Writer}

Researchers at Boston University have suggested that using simple sugars as adjuvants could enhance the ability of aminoglycoside antibiotics to treat persistent bacterial infections. ${ }^{1}$ The strategy could help improve the efficacy of Novartis AG's inhaled aminoglycoside Tobi tobramycin for treating Pseudomonas aeruginosa infection in cystic fibrosis. The results also might open a new therapeutic opportunity for Pharmaxis Ltd.'s inhaled Bronchitol mannitol solution, which is in late-stage development for improving mucous clearance in the lungs of patients with cystic fibrosis.

Bacterial persistence occurs when a subpopulation within a bacterial population decreases its growth rate, thus becoming less sensitive to killing by growth-inhibiting antibiotics. ${ }^{2}$ This occurs in biofilms, for example, which are surface-attached bacterial communities held together by extracellular polymeric matrices.

In addition to $P$. aeruginosa, clinically relevant, persistent bacterial infections include Staphylococcus aureus infection of catheters and surgical implants, and urinary tract infections (UTIs) caused by Escherichia coli.

A team led by James Collins, professor of biomedical engineering at $\mathrm{BU}$, investigator at the

Howard Hughes Medical Institute and a founding member of the Wyss Institute for Biologically Inspired Engineering at Harvard University, set out to identify new strategies to treat these persistent bacterial infections. The researchers reasoned that if they could stimulate the growth of the semidormant subpopulation of bacteria, they could increase the efficacy of antibiotics that kill bacteria by inhibiting active processes such as cell division and protein synthesis.

"The great majority of antibiotics work on happily growing cells, and we reasoned that if we could wake up the persisters, we could kill them off," Collins told SciBX.

The group exposed persistent $E$. coli to a panel of sugars and a battery of commonly used antibiotics.

The results were surprising. Gentamicin, a generic aminoglycoside antibiotic, decreased persistent bacteria more than 1,000-fold in the presence of common sugars such as glucose and mannitol. But the sugars had no effect on the efficacy of other commonly used antibiotics, including the $\beta$-lactam ampicillin and the fluoroquinolone ofloxacin.

However, contrary to the researchers' hypothesis, gentamicin's effect did not appear to be due to a resumption of growth. Although these sugars did indeed revive bacteria after many hours, the researchers saw increased killing as soon as one hour after exposure, too soon for the bacteria to begin dividing.

Collins and his team turned to metabolic network analysis to pinpoint what could account for these observations and found that the sugars rapidly increased proton motive force, which is a process by which ATP is generated via the transfer of hydrogen ions across the bacterial membrane. Proton motive force has long been known to play a role in aminoglycoside uptake. ${ }^{3}$

The team then used a catheter-implanted mouse model of $E$. coli UTI to test the clinical relevance of these observations. Co-treatment with gentamicin and mannitol lowered biofilm viability by 50 -fold and prevented the spread of bacteria to the kidneys compared with gentamicin treatment alone.

Finally, to show this effect was not E. coli-specific, the researchers found that fructose could enhance gentamicin killing of persistent S. aureus by 100 -fold.

Results were published in Nature.

\section{A lung full of sugar}

Companies contacted by SciBX suggested the most obvious clinical application of the findings could be in treating CF patients infected with

\section{P. aeruginosa.}

Up to $80 \%$ of patients with CF develop chronic $P$. aeruginosa infections by age 18 . In healthy individuals, mucociliary clearance and a robust immune response keep the respiratory tract clear of infection. But in CF patients, the lungs are filled with mucus that is not effectively cleared, providing a fertile environment for the bacteria to form biofilms.

"The persister problem is most acute in Pseudomonas - it is a huge problem: the bacteria are in a nasty biofilm state that can't be cleared out. CF patients are constantly getting antibiotics because they can't clear the infection," J. Kevin Judice, $\mathrm{CEO}$ and CSO of Achaogen Inc., told SciBX.

Achaogen is developing next-generation aminoglycosides that can overcome antibiotic resistance. The company's lead compound, ACHN490, is in Phase II testing to treat complicated UTI and acute pyelonephritis.

Erin Duffy, VP of discovery research at Rib-X Pharmaceuticals Inc., said she was enthusiastic about the basic science findings, noting that "the unmet medical need in treating persisters is very high. People have dabbled in trying to understand mechanisms of persistence, and this work is a step towards a specific strategy to treat persisters."

Two inhaled antibiotics are marketed to treat CF patients infected with P. aeruginosa: Tobi, which was approved in 1997, and Cayston aztreonam, a monolactam from Gilead Sciences Inc. that was approved last February.

According to Judice, the obvious next step "would be to take this finding, reformulate Tobi in mannitol and see if it does better in treating infection." 
Prabhavathi Fernandes, founder, president and CEO of Cempra Pharmaceuticals Inc., agreed. "You might be able to mix Tobi with other sugars as an aerosol treatment in the lungs." However, other organs could be more difficult to reach efficiently, she cautioned.

Novartis declined to comment on the clinical potential of the reported findings.

Cempra's solithromycin (CEM-101), a new macrolide antibiotic, is in Phase II testing for community-acquired pneumonia (CAP). The company is also developing Taksta (fusidic acid), which has completed Phase II trials for acute bacterial skin and skin structure infections (ABSSSIs).

Pharmaxis is developing Bronchitol mannitol, an inhaled dry powder formulation of mannitol intended for decreasing mucous buildup in patients with CF. The drug is approved in Australia to treat CF. Last month, the company said the EMA's Committee for Medicinal Products for Human Use (CHMP) indicated it is unlikely to approve an MAA in Europe. ${ }^{4}$

A Pharmaxis spokesperson told SciBX that it is too early to tell what the impact of these discoveries might be, but they will be the topic of future discussions with their clinical advisors.

\section{Clinical issues}

Although the findings suggest a potential approach to treating persistent bacterial infections, additional questions must be answered to prove clinical relevance.

Kim Lewis, professor and director of the Antimicrobial Discovery Center at Northeastern University, said the basic findings were impressive but clinical application would be "considerably more complicated, as there are already high levels of glucose in the blood. It's not clear to me that adding a different sugar or more sugar would have a clinical effect."

Lewis' group has published research on the emergence of antibiotic tolerance. His team is focused on developing new therapeutics to eliminate persisters.

Achaogen's Judice said a next step would be to test the hypothesis in mouse models of Pseudomonas infection. He also wanted to know if the approach would lower the minimum inhibitory concentration (MIC) and increase the potency of aminoglycosides for all bacteria in a population, not simply the persisters.

Duffy said an added complication is the emergence of drug-resistant strains of $P$. aeruginosa in CF patients who are repeatedly treated with antibiotics. "Drug resistance and persistence go hand in hand," she said.
She suggested looking at the effect of this approach on a range of strains with different levels of aminoglycoside resistance.

Rib-X's delafloxacin, a next-generation fluoroquinolone, is in Phase IIb testing to treat ABSSSIs. The company also is developing radezolid, a new oxazolidinone that has completed two Phase II trials for CAP and uncomplicated skin and skin structure infections. In lead optimization, their RX-04 program has produced three novel classes of ribosome-targeting antibiotics, with potency and efficacy against drug-resistant Gram-negative pathogens like P. aeruginosa.

Finally, Duffy pointed out that most regulations in place to develop antibiotics measure activity against nonpersistent bacteria, and to develop a drug and show proof of concept for treating a persistent population would require a team effort between companies and regulators.

Collins told SciBX his lab is not pursuing studies in Pseudomonas, but said, "This is a highly promising possibility for the near term. We think the effect will work on Pseudomonas." His team plans to search for metabolites that could cause a similar effect in Mycobacterium tuberculosis, another highly persistent respiratory pathogen.

Collins said a patent has been filed covering his lab's findings, and they are available for licensing.

Cain, C. SciBX 4(23); doi:10.1038/scibx.2011.647

Published online June 9, 2011

\section{REFERENCES}

1. Allison, K.R. et al. Nature; published online May 11, 2011; doi:10.1038/nature10069

Contact: James J. Collins, Boston University, Boston, Mass. e-mail: jcollins@bu.edu

2. Lewis, K. Annu. Rev. Microbiol. 64, 357-372 (2010)

3. Taber, H.W. et al. Microbiol. Rev. 51, 439-457 (1987)

4. Lawrence, S. BioCentury 19(23), A18-A22; May 30, 2011

COMPANIES AND INSTITUTIONS MENTIONED

Achaogen Inc., South San Francisco, Calif.

Boston University, Boston, Mass.

Cempra Pharmaceuticals Inc., Chapel Hill, N.C. Gilead Sciences Inc. (NASDAQ:GILD), Foster City, Calif. Howard Hughes Medical Institute, Chevy Chase, Md. Northeastern University, Boston, Mass.

Novartis AG (NYSE:NVS; SIX:NOVN), Basel, Switzerland Pharmaxis Ltd. (ASX:PXS; Pink:PXSLY), Frenchs Forest, New South Wales, Australia

Rib-X Pharmaceuticals Inc., New Haven, Conn.

Wyss Institute for Biologically Inspired Engineering at Harvard University, Cambridge, Mass. 